\title{
Avaliação da Dispersão primária e secundária do Tomato severe rugose virus para genótipos de Capsicum spp. por Bemisia tabaci MEAM1
}

\author{
Késsia de Fátima Cunha Pantoja ${ }^{1}$; Kelly Cristina Gonçales Rocha; Edson Luiz Lopes Baldin; Marcelo Agenor \\ Pavan $^{1}$; Renate Krause-Sakate ${ }^{1}$
}

${ }^{1}$ Departamento de Proteção Vegetal, Faculdade de Ciências Agronômicas, FCA-Unesp, CEP 18610-307, Botucatu, SP.

Autor para correspondência: Renate Krause Sakate (renatekrause@fca.unesp.br)

Data de chegada: 25/04/2014. Aceito para publicação em: 29/09/2014.

$10.1590 / 0100-5405 / 2001$

\section{RESUMO}

Pantoja, K.F.C.; Rocha, K.C.G.; Baldin, E.L.L.; Pavan, M.A.; Krause-Sakate, R. Avaliação da Dispersão primária e secundária do Tomato severe rugose virus para genótipos de Capsicum spp. por Bemisia tabaci MEAM1. Summa Phytopathologica, v.40, n.4, p.375-377, 2014.

A mosca branca Bemisia tabaci (Hemiptera: Aleyrodidae) é considerada uma das pragas agrícolas mais ameaçadoras em todo o mundo, pelo seu efeito direto na sucção de seiva das plantas e principalmente pelo seu efeito indireto de transmitir vírus, em especial os begomovírus. No Brasil, a espécie de begomovírus predominante em solanáceas é o Tomato severe rugose vírus - ToSRV. Uma possibilidade de manejo da doença é a utilização de cultivares resistentes ou tolerantes tanto ao vírus, como ao inseto vetor. Foram avaliados neste trabalho a dispersão primária e secundária do ToSRV por Bemisia tabaci, espécie MEAM1, também conhecida como biótipo $B$, em cultivares tolerantes ao ToSV Capsicum baccatum (IAC-1357) C. annuum (IAC-1566) e $C$. frutescens (IAC-1544). O genótipo (IAC-1544) apresentou menor número de plantas infectadas pelo ToSRV no ensaio de dispersão primária e nenhuma eficiência na transmissão do isolado na dispersão secundária. Estes resultados colaboram para o melhoramento de pimentão e pimentas visando a resistência ao ToSRV e seu inseto vetor.

Palavras-chave adicionais: Transmissão, atratividade, Capsicum, begomovírus.

\section{ABSTRACT}

Pantoja, K.F.C.; Rocha, K.C.G.; Baldin, E.L.L.; Pavan, M.A.; Krause-Sakate, R. Evaluation of the primary and secondary dispersal of Tomato severe rugose virus to Capsicum spp. genotypes by Bemisia tabaci MEAM1. Summa Phytopathologica, v.40, n.4, p.375-377, 2014.

The whitefly Bemisia tabaci (Hemiptera : Aleyrodidae) is considered one of the most threatening agricultural pests in the world due to its direct effect on the suction of sap from plants and especially due to its indirect effect in transmitting viruses, particularly the begomovirus. In Brazil, the predominant species of begomovirus within Solanaceae is Tomato severe rugose virus - ToSRV. A possibility of management of this disease is the use of cultivars that are resistant or tolerant to both the virus and the insect vector. This study evaluated the primary and secondary dispersal of ToSRV by B. tabaci, MEAM1 species, also known as biotype B, usin ToSRV-tolerant species Capsicum baccatum (IAC-1357), C. annuum (IAC -1566) and C. frutescens (IAC-1544). The genotype IAC -1544 showed a smaller number of plants infected by ToSRV during the primary dispersal assay and no efficiency in the isolate transmission in the secondary dispersal. These results contribute to capsicum and pepper breeding forresistance to ToSRV and its insect vector.

Additional keywords: transmission, attractiveness, Capsicum, begomoviruses.

O gênero Capsicum (Solanaceae), apresenta grande importância agrícola e é largamente cultivado nas regiões temperadas e tropicais do mundo (8). Apesar dos avanços tecnológicos incorporados na produção, doenças de origens bióticas e abióticas ainda interferem na produção, com destaque para aquelas causadas por vírus (7).

As doenças de etiologia viral podem limitar a produção de pimentas e pimentões. No Brasil, vários vírus infectam estas culturas, dentre eles, duas espécies de begomovírus que foram relatados inicialmente no Submédio do Vale São Francisco, que compreende os estados da Bahia e Pernambuco $(4,5)$ e posteriormente, no Estado de São Paulo em 2005 (6). Estas espécies são Tomato severe rugose virus (ToSRV) e Tomato yellow vein streak virus (ToYVSV), sendo o ToSRV prevalente $(9,10)$. A dispersão e a transmissão de begomovírus, no campo, ocorre pela ação da mosca branca, Bemisia tabaci (12). A relação begomovírusBemisia tabaci é de modo circulativa, persistente e não propagativa
(1). A capacidade de transmissão varia entre os biótipos, no entanto o biótipo B apresenta maior facilidade de transmissão de diferentes isolados virais (3).

Três genótipos de Capsicum, com diferenças relacionadas à suscetibilidade ao ToSRV e atratividade para $B$. tabaci (7), foram selecionados para verificar a dispersão primária e secundária realizada pela transmissão por esse vetor. Para tanto, sementes de Capsicum baccatum (IAC-1357) (sintomático ao ToSRV e atrativo à mosca branca); C. frutescens (IAC-1544) (assintomático ao ToSRV e pouco atrativo à mosca branca) e C. annuum (IAC-1566) (assintomáticos e pouco atrativo à mosca branca) foram fornecidos gentilmente pelo Instituto Agronômico de Campinas/IAC, para a repetição de ensaios de atratividade sem chance de escolha. Estes genótipos foram previamente selecionados, pois a média de ovos após 48 horas de liberação de moscas brancas, nos genótipos IAC-1357 e IAC-1566 
é de aproximadamente 4,2 e 5,0 respectivamente, enquanto que para IAC-1544 é de 0,6, indicando a baixa atratividade do inseto a este último genótipo (7).

Os ensaios de dispersão primária para cada genótipo contaram com adultos de moscas brancas que foram previamente submetidos a um período de acesso de aquisição (PAA) de 24 horas em ramos de plantas de tomate 'Santa Clara' infectados por ToSRV (confirmação por RCA-PCR). Após este período, as moscas brancas foram aspiradas com auxílio de um aspirador bucal, (média de 30 adultos/planta) e, posteriormente, liberadas no centro de uma arena circular constituída por 20 plantas de cada genótipo. Esta fase experimental foi executada no interior da gaiola metálicas de 2,5 x 3,0 x 2,5m com laterais revestidas por telado anti-afídeo, e para o experimento foram utilizadas três gaiolas isoladas para cada genótipo (Figura 1A). As plantas permaneceram por um período de acesso de inoculação (PAI) de $48 \mathrm{~h}$, sendo posteriormente tratadas com inseticida e transferidas para casa-de-vegetação livres de mosca branca. A observação de sintomas foi realizada semanalmente e a constatação da presença do vírus foi realizada aos 30 dias após inoculação por RCA-PCR, de acordo com Inoue-Nagata et al. (2).

Os ensaios de dispersão secundária para cada genótipo foram realizados nas mesmas gaiolas, porém, previamente pulverizadas com inseticida para eliminação de moscas-brancas remanescentes no ensaio de dispersão primária. Para cada ensaio foram utilizadas 20 plantas sadias de cada genótipo, dispostas em círculo sendo o centro deste círculo constituído por três plantas infectadas com o ToSRV sempre pelos mesmo genótipos estudados. No centro das plantas infectadas foram liberados, em média, 30 insetos por planta de B. tabaci MEAM1 livres de vírus por planta, totalizando 600 insetos (Figura 1B). Após 48 horas da liberação das moscas brancas todas as plantas foram pulverizadas com inseticida específico para $B$. tabaci MEAM1 e as plantas transferidas para casa-de-vegetação com tela anti-afídica. A transmissão do vírus foi confirmada por RCA-PCR, 30 dias após inoculação e a expressão dos sintomas.

No experimento 1 de dispersão primária do ToSRV, 9 plantas (45\%) de C. annuum IAC-1566 e 6 plantas (30\%) de C. baccatum IAC-1357 foram positivas em RCA-PCR 30 dias após o período de acesso de inoculação. $\mathrm{Na}$ dispersão primária (experimento 2), 12 plantas (60\%) do genótipo IAC-1357 e 6 (30\%) do genótipo IAC-1544 foram consideradas positivas (Tabela 1). O experimento de dispersão primária corrobora com os dados previamente obtidos por Pantoja
(7), em que verificou menor oviposição no genótipo 1544, e que foi o menos infectado neste experimento, indicando que a baixa atratividade observada no experimento sem chance de escolha pode refletir, na prática, em baixa porcentagem de plantas infectadas pelo begomovírus. Já para o genótipo IAC-1566, este propiciou maior oviposição quando comparado ao IAC-1357 (7), e foi constatado maior número de plantas infectados quando comparadas ao último genótipo, evidenciando a correlação direta entre atratividade da planta ao inseto e número de plantas infectadas pelo ToSRV.

$\mathrm{Na}$ dispersão secundária do experimento 1 foram observadas $3(15 \%)$ plantas positivas para cada um dos genótipos IAC-1357 e IAC-1566, no experimento 2, $1(5 \%)$ e 0 plantas para os genótipos IAC-1357 e IAC-1544, respectivamente, aos 30 dias após inoculação (D.A.I.) (Tabela 1). Apesar da baixa transmissão do ToSRV no ensaio de transmissão secundária, pode-se observar a tendência de maior número de plantas infectadas nos genótipos IAC-1357 e IAC-1566, o que também pode ser explicado pela maior atratividade ao inseto (7). O mesmo autor verificou que o genótipo IAC - 1544, não permite o desenvolvimento larval de mosca-branca, sem emergência de adultos, esse fato permite concluir em menor dispersão do ToSRV por $B$. tabaci MEAM1.

Avaliações já realizadas relatam a redução na dispersão primária e secundária do TYLCV em tomateiros pouco atrativos à $\mathrm{B}$. tabaci (11). Esta resistência ao inseto foi associada à presença de tricomas glandulares do tipo IV e à produção de acylsucrose, inibindo a alimentação da mosca - branca e diminuição, consequentemente, a capacidade de atingir o floema.

Comparando os resultados de dispersão primária e secundária do ToSRV, nos três genótipos de Capsicum, pode-se inferir que a maior eficiência de transmissão deste begomovírus é beneficiada pela presença de moscas brancas virulíferas provenientes de tomateiro infectado (migração de vetores virulíferos de uma cultura de tomateiro para o pimentão). No entanto, o uso de genótipos com baixa atratividade de $B$. tabaci biótipo B (MEAM1) e com efeito negativo no desenvolvimento do inseto, pode resultar em uma menor dispersão do ToSRV dentro de um cultivo, e ainda impedir a disseminação para outras culturas de solanáceas.

\section{AGRADECIMENTO}

Os autores agradecem à Dra. Arlete Marchi Tavares Melo,

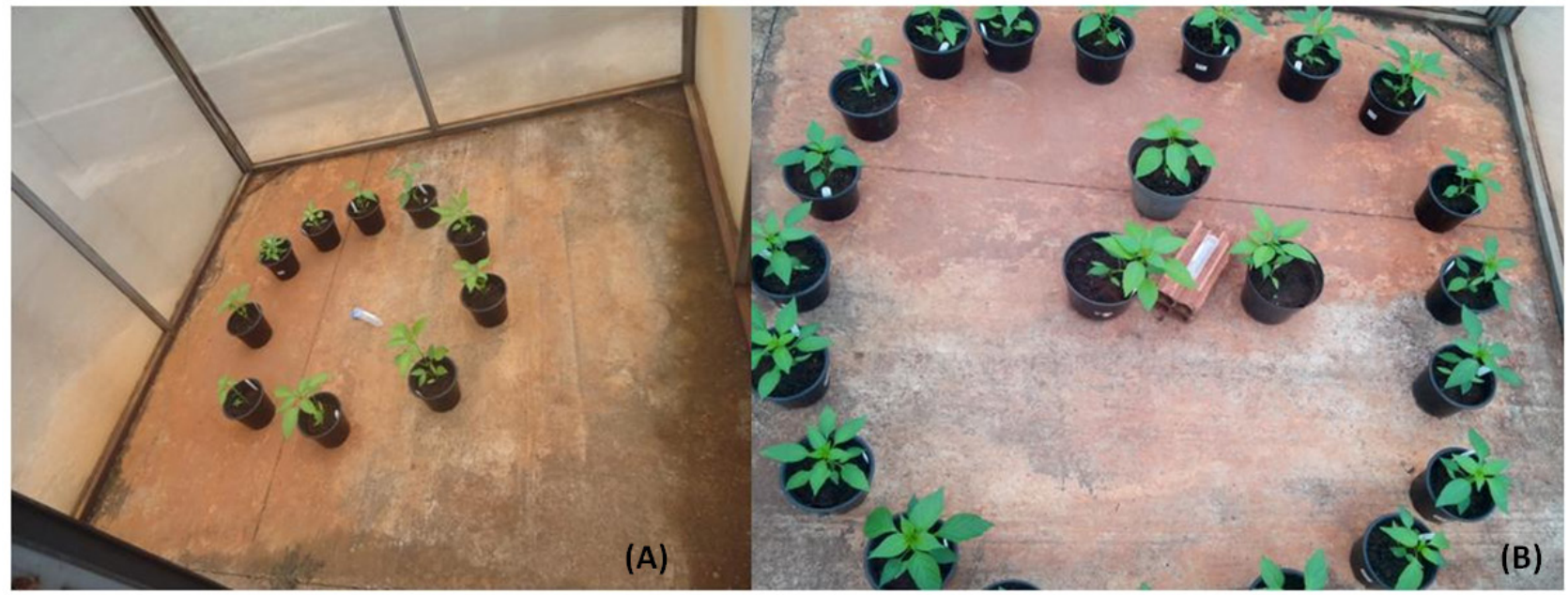

Figura 1. Modelo do ensaio de dispersão primária (A) e secundária (B) do ToSRV por B. tabaci (biótipo B) para os genótipos de Capsicum IAC-1357; IAC-1544 e IAC-1566. 
Tabela 1. Dispersão primária e secundária de ToSRV para genótipos de Capsicum spp. utilizando B. tabaci MEAM1 para transmissão.

\begin{tabular}{|c|c|c|c|c|c|c|c|c|c|}
\hline \multirow{3}{*}{$\begin{array}{c}\text { Plantas } \\
\text { desafiadas }\end{array}$} & \multicolumn{2}{|c|}{ Dispersão Primária } & \multicolumn{2}{|c|}{ Dispersão Secundária } & \multirow{3}{*}{$\begin{array}{c}\text { Plantas } \\
\text { desafiadas }\end{array}$} & \multicolumn{2}{|c|}{ Dispersão Primária } & \multicolumn{2}{|c|}{ Dispersão Secundária } \\
\hline & IAC-1357 & IAC-1566 & IAC-1357 & IAC-1566 & & IAC-1357 & IAC-1544 & IAC-1357 & IAC-1544 \\
\hline & 30DAI & 30DAI & 30DAI & 30DAI & & 30DAI & 30DAI & 30DAI & 30DAI \\
\hline 1 & & & & + & 1 & + & & & \\
\hline 2 & & & & & 2 & + & + & & \\
\hline 3 & & + & & & 3 & + & + & & \\
\hline 4 & + & + & & & 4 & + & + & & \\
\hline 5 & & + & & & 5 & + & + & & \\
\hline 6 & & + & + & & 6 & + & + & & \\
\hline 7 & & + & & & 7 & + & & & \\
\hline 8 & + & & + & & 8 & + & + & & \\
\hline 9 & & + & & & 9 & + & & & \\
\hline 10 & & & & & 10 & & & & \\
\hline 11 & & & & & 11 & & & & \\
\hline 12 & & & + & & 12 & + & & & \\
\hline 13 & + & & & & 13 & & & & \\
\hline 14 & + & & & & 14 & & & & \\
\hline 15 & + & + & & & 15 & + & & & \\
\hline 16 & & & & & 16 & & & & \\
\hline 17 & & & & & 17 & & & & \\
\hline 18 & & + & & + & 18 & & & & \\
\hline 19 & & & & + & 19 & & & & \\
\hline 20 & + & + & & & 20 & + & & + & \\
\hline $\begin{array}{l}\text { N. pl infec/ } \\
\text { N. pl aval }\end{array}$ & $6 / 20$ & $9 / 20$ & $3 / 20$ & $3 / 20$ & $\begin{array}{l}\text { N. pl infec/ } \\
\text { N.pl aval }\end{array}$ & $12 / 20$ & $6 / 20$ & $1 / 20$ & $0 / 20$ \\
\hline $\begin{array}{c}\text { Porcentagem } \\
\text { de plantas } \\
\text { infectadas }\end{array}$ & $30 \%$ & $45 \%$ & $15 \%$ & $15 \%$ & $\begin{array}{c}\text { Porcentagem } \\
\text { de plantas } \\
\text { infectadas }\end{array}$ & $60 \%$ & $30 \%$ & $5 \%$ & $0 \%$ \\
\hline
\end{tabular}

pesquisadora do Instituto Agronômico de Campinas, pelo fornecimento dos genótipos de Capsicum. RKS, MAP e ELLB são bolsistas de produtividade do CNPq.

\section{REFERÊNCIAS BIBLIOGRÁFICAS}

1. Hull,R. Matthew's plant virology. Nem York Press, 1001 p. 2002.

2. Inoue-Nagata, A.K.; Albuquerque, L.C.; Rocha, W.B.; Nagata, T. A simple method for cloning the complete begomovirus genome using the bacteriophage phi29 DNA polymerase. Journal of Virological Methods, Amsterdam, v.116, p.209-211, 2004.

3. Jones, D.A.; Dickinson, M.J.; Balint-Kurti, P.J.; DIxon, M.S.; Jones, J.D.G. Two complex resistance loci revealed in tomato by classical and RFLP mapping of the cf-2, cf-4, cf-5 and cf-9 genes for resistence to cladosporium fulvum. Molecular Plant-Microbe Interaction. p.348-357, 2003.

4. Lima, M.F.; Bezarra, I.C.; Ribeiro, S.G.; Avila, A.C. Distribuição de geminivírus nas culturas do tomate e pimentão em doze municípios do Submédio do Vale São Francisco. Fitopatologia Brasileira, Fortaleza, v. 26, n. 1, p. 81-85, 2001.

5. Lima, M.F.; Bezerra, I.C.; Ribeiro, S.G.; Ávila, A.C. Detection of sweet pepper whitefly-transmited geminivírus in the "Submédio" of San Francisco Valley. In: $22^{\circ}$ congresso paulista de fitopatologia, 22.,1999, Jaboticabal. Anais, Jaboticabal: Editora, 1999. p. 106.

6. Nozaki, D.N. Estudos biológicos e moleculares de begomovírus infectando pimentão (Capsicum annuum) no estado de São Paulo. 2007. 94 f. Tese (Doutorado em Agronomia/Proteção de Plantas)-Faculdade de
Ciências Agronômicas, Universidade Estadual Paulista, Botucatu.

7. Pantoja, K.F.C. Ocorrência de begomovírus em plantas de pimentão no estado de São Paulo e comportamento de genótipos de Capsicum spp. ao Tomato severe rugose virus e a Bemisia tabaci MEAM1. 2014. 62 f. Dissertação (Mestrado em Agronomia/Proteção de Plantas)-Faculdade de Ciências Agronômicas, Universidade Estadual Paulista, Botucatu.

8. Pozzobon, M.T.; Wittmann, M.T. A meiotic study of the wild and semi domesticated Brazilian species of genus Capsicum L. (Solanaceae). Cytologia, Tokyo, v.71, n. 3, p. 275-287, 2006.

9. Rocha, K.C.G.; Krause-Sakate. R.; Pavan, M. A.; Kobori, R. F.; Gioria, R.; Yuki, V. A. Avaliação de danos causados pelo Tomato severe rugose virus (ToSRV) em cultivares de pimentão. Summa Phytopathologica, Botucatu, v. 38, 87-89. 2012.

10. Rocha, K.C.G.; Marubayashi, J.M.; Navas-Castillo, J.; Pavan, M.A.; Krause-Sakate, R. Ocorrência e variabilidade genética do Tomato severe rugose virus em tomateiro e pimentão no Estado de São Paulo. Summa Phytopathologica, Botucatu, v. 36, p. 222-227, 2010.

11. Rodríguez-López, M.J.; Garzo, E.; Bonani, J.P.; Fereres, A.; FernándezMunoz, R.; Moriones, E. Whitefly resistance traits derived from the wild tomato Solanum pimpinelli folium affect the preference and feeding behavior of Bemisia tabaci and reduce the spread of Tomato yellow leaf curl virus. Phytopathology, St. Paul, v. 101, p. 1191-1201, 2011.

12. Stanley, J. Bisaro, D.M., Briddon, R.W., Brown, J.K., Fauquet, C.M., Harrison, B.D., Rybicki, E.P., Stenger, D.C.Geminiviridae. In Fauquet, C. M.; Mayo, M. A.; Mmaniloff, J., Dessselberger, U., Ball L.A. (eds), Virus taxonomy: eighth Report of the International Committee on Taxonomy of Viruses. London: Elsevier, 2005. p. 301-326. 